\title{
La polémique au XVII siècle, sous la direction de Gérard Ferreyrolles
}

\section{Cristina Musio}

\section{(2) OpenEdition}

\section{Journals}

\section{Edizione digitale}

URL: https://journals.openedition.org/studifrancesi/45742

DOI: 10.4000/studifrancesi.45742

ISSN: 2421-5856

\section{Editore}

Rosenberg \& Sellier

\section{Edizione cartacea}

Data di pubblicazione: 1 octobre 2007

Paginazione: 433-434

ISSN: 0039-2944

\section{Notizia bibliografica digitale}

Cristina Musio, «La polémique au xvII siècle, sous la direction de Gérard Ferreyrolles», Studi Francesi

[Online], 152 (LI | II) | 2007, online dal 30 novembre 2015, consultato il 24 novembre 2021. URL: http:// journals.openedition.org/studifrancesi/45742 ; DOI: https://doi.org/10.4000/studifrancesi.45742

Questo documento è stato generato automaticamente il 24 novembre 2021.

\section{@(๑) $\Theta \Theta$}

Studi Francesi è distribuita con Licenza Creative Commons Attribuzione - Non commerciale - Non opere derivate 4.0 Internazionale. 


\title{
La polémique au XVII siècle, sous la direction de Gérard Ferreyrolles
}

\author{
Cristina Musio
}

\section{NOTIZIA}

La polémique au XVII eiècle, sous la direction de Gérard FERREYROLLES, «Littératures classiques», n. 59, été 2006.

1 Il numero 59 di Littératures Classiques è incentrato per intero su di un tema capitale per gli studiosi del xvii secolo, quello della polemica. Nel saggio introduttivo, Le xvii siècle et le statut de la polémique (pp. 5-27), Gérard Ferreyrolles spiega come questo secolo sia stato caratterizzato da controversie praticamente in ogni ambito: dalla religione alla politica, dalla filosofia alla matematica, dalla pittura alla letteratura. Dopo un tentativo di definizione del discorso polemico (Situation du discours polémique), l'A. delinea le principali condizioni del suo funzionamento (Fonctionnement du discours polémique), «dualité des discours, terrain commun à leur affrontement, présence d'un troisième actant et bipolarité». Una caratteristica fondamentale del discorso polemico è quella che Ferreyrolles definisce spécularité (Spécularités polémiques), ossia la tendenza dei polemisti a riflettere non solo sulla metodologia, ma anche sull'etica della loro pratica.

2 I saggi sono suddivisi in tre sezioni, dedicate rispettivamente alle forme, alle norme e ai campi della polemica. La prima sezione, «Les formes de la polémique», comprende $\mathrm{i}$ seguenti articoli:

Claudine NÉDÉLEC, Burlesques et polémiques, pp. 31-46;

4 Anne TOURNON, Les textes palmarès allégoriques, pp. 47-66;

5 Nicolas PIQUÉ, La controverse religieuse: questions de méthode et dynamique de la confrontation, pp. 67-76;

6 Jacques LE BRUN, Mutations du débat philosophique et théologique à la fin du XVII siècle et au début du XVIII, pp. 77-92. 
La seconda sezione, «Les normes de la polémique», consta dei seguenti contributi:

Dominique DESCOTES, Mersenne polémiste, pp. 95-115;

Olivier JousLIN, L'éthique polémique de Pascal, pp. 117-139;

Delphine REGUIG-NAYA, Antoine Arnauld polémiste: de l'urgence de théoriser, pp. 141-155;

Béatrice GUION, «Une dispute honnête»: la polémique selon les Modernes, pp. 157-172.

La terza e ultima sezione, «Les champs de la polémique», contiene articoli relativi alla polemica in campo letterario, sociale, politico e religioso. I primi tre riguardano il campo letterario:

Mathilde BOMBART, Des écritures en polémique: autour de la querelle des "Lettres" de Guez de Balzac (1624-1630), pp. 177-191;

4 Jean-Marc CIVARDI, Bibliographie critique des querelles théâtrales en France au XVII siècle, pp. 193-221;

Camille ESMEIN, Polémique et réflexion sur le genre romanesque au XVII siècle: la fortune du débat pour ou contre le roman, pp. 223-235.

I seguenti articoli riguardano il campo sociale e politico:

Jean-Claude ARNOULD, Marie de Gournay polémique, pp. 239-250;

Myriam DUFOUR-MAITRE, Les précieuses, de la guerre des sexes aux querelles du Parnasse: jalons d'une polémique empêchée, pp. 251-263;

Coralie ROBIN, L"Histoire amoureuse des Gaules" de Bussy-Rabutin: cantique de la médisance ou machine de guerre?, pp. 265-282.

Infine, gli ultimi quattro articoli concernono la polemica in campo religioso:

Aurélien HUPÉ, La revanche de la logique sur la rhétorique: la controverse entre Philippe Goibaut Du Bois et Antoine Arnauld sur l'éloquence sermonnaire, pp. 285-298;

Anne FERRARI, Bossuet et Fénelon: la lettre qui tue, pp. 299-316;

Pauline CHADUC, Le texte et son auteur: la querelle du sens dans la controverse entre Fénelon et Bossuet, pp. 317-333;

Geneviève ARTIGAS-MENANT, La polémique religieuse chez Robert Challe, pp. 335-349.

Il volume si chiude con un'utilissima bibliografia curata da Gérard Ferreyrolles. 